University of Nebraska - Lincoln

DigitalCommons@University of Nebraska - Lincoln

Publications from USDA-ARS / UNL Faculty

U.S. Department of Agriculture: Agricultural

Research Service, Lincoln, Nebraska

2015

Visual and olfactory enhancement of stable fly trapping

Junwei J. Zhu

USDA-ARS, jerry.zhu@ars.usda.gov

Qing-he Zhang

Sterling International, Inc.

David B. Taylor

USDA-ARS, dave.taylor@ars.usda.gov

Kristina A. Friesen

USDA-ARS, kristina.friesen@ars.usda.gov

Follow this and additional works at: https://digitalcommons.unl.edu/usdaarsfacpub

Zhu, Junwei J.; Zhang, Qing-he; Taylor, David B.; and Friesen, Kristina A., "Visual and olfactory enhancement of stable fly trapping" (2015). Publications from USDA-ARS / UNL Faculty. 1555.

https://digitalcommons.unl.edu/usdaarsfacpub/1555

This Article is brought to you for free and open access by the U.S. Department of Agriculture: Agricultural Research Service, Lincoln, Nebraska at DigitalCommons@University of Nebraska - Lincoln. It has been accepted for inclusion in Publications from USDA-ARS / UNL Faculty by an authorized administrator of DigitalCommons@University of Nebraska - Lincoln. 


\title{
Visual and olfactory enhancement of stable fly trapping
}

\author{
Junwei J Zhu, ${ }^{a^{*}}$ Qing-he Zhang, ${ }^{b}$ David B Taylor ${ }^{a}$ and Kristina A Friesen ${ }^{a}$
}

\begin{abstract}
BACKGROUND: Stable flies are considered to be one of the major blood-feeding pests in the US livestock industry, causing losses running into billions of dollars annually. Adult stable flies are highly attracted to Alsynite traps; however, Alsynite is becoming increasingly difficult to obtain and is expensive.

RESULTS: Here, we report on the development of a less expensive and more efficacious trap based upon a white panel with the option to add visual and olfactory stimuli for enhanced stable fly trapping. White panel traps caught twice as many stable flies than Alsynite traps. Baiting the traps with synthetic manure volatiles increased catches 2-3-fold. Electroretinographic recordings of stable flies showed strong peaks of visual sensitivities occurring at 330-360 nm, 460-525 nm and 605-635 nm. A laboratory study indicated that young stable flies are more responsive to white, whereas gravid females prefer blue; in the field, white traps caught more stable flies than patterned or blue-black traps.
\end{abstract}

CONCLUSION: Stable fly control can be enhanced by developing more efficient trapping systems with added visual and olfactory stimuli.

Published 2015. This article is a U.S. Government work and is in the public domain in the USA.

This document is a U.S. government work and is not subject to copyright in the United States.

Keywords: Stomoxys calcitrans; visual response; attractant; enhanced trapping

\section{INTRODUCTION}

Stable flies, Stomoxys calcitrans (Diptera: Muscidae), are major blood-feeding pests of bovids and equids in livestock barns and stables. ${ }^{1}$ Taylor et al. ${ }^{2}$ reported that stable flies cause over \$US 2 billion annually in losses to the US cattle industry. These flies can be serious pests of humans as well when their primary hosts are absent.

Stable fly control in confined and pastured livestock settings has focused primarily on sanitation and insecticides. However, sanitation procedures are costly, and insecticides provide only marginal control. ${ }^{3,4}$ Furthermore, insecticide resistance in stable flies has been detected, primarily with organochlorine and organophosphate insecticides. ${ }^{3,5}$ Recently, Pitzer et al. ${ }^{6}$ identified several field populations of stable flies in Florida that were resistant to permethrin, the most commonly used insecticide for stable fly management.

Traps with sticky surfaces have been used to monitor and control stable fly populations. ${ }^{7-12}$ Most stable fly traps are made of adhesive-coated translucent fiberglass panels (Alsynite), first developed by Williams ${ }^{10}$ and later improved by Broce. ${ }^{13}$ Rugg $^{14}$ has reported a significant reduction in stable fly populations (79\% in 7.5 days) via the deployment of Williams traps in an Australian zoo. More recently, blue/black cloth targets, based upon the Nzi trap developed for tsetse fly (Glossina spp.) control, ${ }^{15}$ have been investigated for population monitoring and control of stable flies. ${ }^{16,17}$

Several studies have also shown that volatile odorants associated with hosts and their environments are used by stable flies for host seeking. ${ }^{3,18}$ Attractants may be useful for improving trap efficacy in the mass trapping of stable flies. ${ }^{17-23}$
In the present study, we (1) compared the efficacy of various stable fly traps, (2) developed a low-cost white panel trap for stable fly monitoring and control, (3) conducted electroretinogram (ERG) recordings of different ages and sexes of stable flies and (4) evaluated the effectiveness of olfactory and visually baited white panel traps for capturing stable flies under field conditions.

\section{METHODS AND MATERIALS}

\subsection{Insects and attractant lures}

Stable flies from a four-year-old colony maintained at the US Department of Agriculture, Agricultural Research Service, Agroecosystem Management Research Unit (Lincoln, NE) were reared at $23 \pm 2{ }^{\circ} \mathrm{C}$ with variable humidity $(30-50 \%)$ and a $12: 12 \mathrm{hL}: \mathrm{D}$ photoperiod. Adults were fed citrated bovine blood $(3.7 \mathrm{~g}$ sodium citrate $L^{-1}$ ) soaked into absorbent pads (Stayfree ${ }^{\circledR}$; McNeil-PPC Inc., Skillman, NJ) placed on top of metal screen cages $(0.5 \times 0.5 \times 0.5 \mathrm{~m})$. Adult flies were sexed within $24 \mathrm{~h}$ of emergence, placed in separate cages and fed with blood.

Attractant lures consisted of $5 \mathrm{~cm}$ long cotton rolls impregnated with $1 \mathrm{mg}$ of phenol, $m$-cresol or $p$-cresol (>95\% purity; Sigma-Aldrich, St Louis, MO) suspended in $1 \mathrm{~mL}$ of ethanol. The

\footnotetext{
* Correspondance to: JJ Zhu, USDA-ARS, AMRU, University of Nebraska, 305B Entomology Hall, Lincoln, NE 68583, USA. E-mail: Jerry.Zhu@ars.usda.gov

a USDA-ARS Agroecosystem Management Research Unit, USDA-ARS, University of Nebraska, Lincoln, NE, USA

b Sterling International, Inc., Spokane, WA 99216, USA
} 


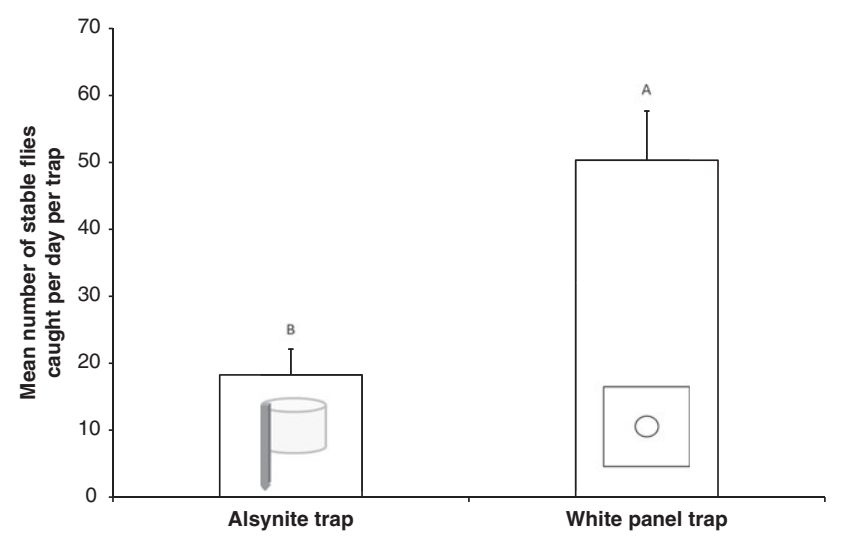

Figure 1. Comparisons of stable fly catches between the Alsynite and white panel traps at the ARDC. Different letters on top of the columns indicate significant differences (Student's $t$-test, $P<0.05$ ).

control lure contained only ethanol $(1 \mathrm{~mL})$. Ethanol was allowed to evaporate under a fume hood for $60 \mathrm{~min}$. Lures with attractant compounds were suspended in the center of $5 \mathrm{~cm}$ diameter holes in the panel traps (Fig. 1).

\subsection{Different types of stable fly trap}

The Alsynite trap tested was a small version ( $18 \mathrm{~cm}$ diameter) of the design presented by Broce ${ }^{13}$ constructed from a $58 \times 58 \mathrm{~cm}$ piece of Alsynite panel. The size was reduced such that the trapping area was similar to that of the panel traps. The trap was covered with 10 mil Sur-Flex plastic (Flex-o-glass, Inc., Chicago, IL) and coated with Tangle-Trap (The Tanglefoot Co., Grand Rapids, MI) diluted 1:1 with low-odor paint thinner (Sunnyside Corp., Wheeling, IL).

White panel traps were made of three different materials: polymer mud flaps $(28 \times 28 \mathrm{~cm}$ and $0.5 \mathrm{~cm}$ thickness; North America's Trucking \& Towing Supplier, Detroit, MI), Coroplast corrugated plastic sheets $(28 \times 28 \mathrm{~cm}$ and $0.5 \mathrm{~cm}$ thickness; Uline Company, Pleasant Prairie, $\mathrm{WI})$ and polystyrene plastic sheets $(28 \times 28 \mathrm{~cm}$ and $0.25 \mathrm{~cm}$ thickness; Home Depot Inc., Lincoln, NE). A $5 \mathrm{~cm}$ diameter hole was cut/drilled in the center of the panels. A transparent plastic sleeve $(58 \times 58 \mathrm{~cm} ; 10$ mil Sur-Flex) with a $5 \mathrm{~cm}$ hole was coated with diluted Tanglefoot and attached to each panel.

\subsection{Electroretinogram recording method}

The ERG system consisted of a lamp that delivered light stimuli to the compound eye of a stable fly through a monochromator that was connected to an optical fiber patch cord (600 $\mu \mathrm{m}$ fiber; Ocean Optics, Inc., Dunedin, FL). Monochromatic light output between 300 and $800 \mathrm{~nm}$ was obtained by passing light from a $75 \mathrm{~W}$ xenon short-arc lamp through an Apex illuminator coupled to an Oriel Cornerstone ${ }^{\mathrm{TM}} 1301 / 8 \mathrm{~m}$ monochromator (Model 70631) with 1200 lines $\mathrm{mm}^{-1}$ and $300 \mathrm{~nm}$ grating (Newport Corporation, Irvine, CA). Light settings for the monochromator were controlled by a controller/shutter system connected to a computer. Light from the monochromator passed into optical fiber patch cord and focused a columnar $0.5 \mathrm{~cm}$ wide beam directly onto the insect eye preparation at a distance of $3 \mathrm{~cm}$. Stimulating flashes lasted $0.5 \mathrm{~s}$, and the interval between flashes was $20 \mathrm{~s}$. Flash stimulation wavelengths between 305 and $795 \mathrm{~nm}$ in increments of $5 \mathrm{~nm}$ were presented randomly to the insect. After 12 stimulations of different wavelengths had been tested, a reference white light was flashed on the insect preparation so that data could be normalized against it later. The entire insect preparation was allowed to adapt to total darkness for 30 min before a spectral sensitivity run was started. The insect remained in the dark between stimulations of light. The room was darkened during operation of recording equipment to minimize light interference from external sources.

The insect preparation for ERG recordings involved cutting all the legs and wings from the body. The live stable fly (4-6 days old and 9-11 days old; both females and males; $n=3$ for each age group per sex) was attached to a holder via dental wax covering the thorax and abdomen. The indifferent tungsten probe was inserted into the thorax, and the recording tungsten electrode was inserted into one of the compound eyes. The ERG signals were recorded via an IDAC-4 intelligent data acquisition controller (Ockenfels Syntech $\mathrm{GmbH}$, Kirchzarten, Germany), stored and analyzed on a PC equipped with the AutoSpike program (Syntech).

\subsection{Different color patterns of stable fly traps}

A visual trap, Rescue Trapstick ${ }^{\circledR}$ for biting flies, was provided by Sterling International, Inc. (Spokane, WA). This trap has a blue, green and yellow multidimensional pattern on a hexagonal pillar. Additional colored traps were built by attaching yellow and white sticky trap cards cut from Pherocon unbaited traps (Trécé, Adair, OK) to the panels of the 'Trapstick ${ }^{\circledR}$ for biting flies' traps with the same surface area (see Fig. 5). Trap catches were analyzed with negative binomial ANOVA (Proc Glimmix, SAS 2012; SAS Institute, Cary, NC).

A laboratory study to test the efficiency of three different colors of Sterling TrapStick for biting flies (http://www.rescue. com/product/trapstik-for-biting-flies) was conducted in cages $(1 \times 1 \times 1 \mathrm{~m})$ at $23^{\circ} \mathrm{C}$ and $50 \% \mathrm{RH}$. It is a hexagon shape of trap made of sticky paper with plastic caps on each end; the trap height is $28 \mathrm{~cm}$. Traps were hung from the cage ceiling in the center of the cage about $30 \mathrm{~cm}$ above the bottom (one type of trap per cage). Approximately 60 stable flies (gravid females or young males and females, 1:1 sex ratio) were released into each cage. The number of flies caught on each trap was counted at $0.5,1,1.5,2$ and $24 \mathrm{~h}$. Each experiment was repeated 5-6 times. Data were analyzed with logistic ANOVA (Proc Glimmix, SAS 2012) with the event/trial format. Independent variables were trap type, fly age and time. All interactions were included in the analysis. Counts were treated as repeated measures with an $A R(1)$ variance structure. Data reported are LS means transformed back to percentages. Tukey's adjustment was used for comparisons among LS means.

We further compared the stable fly catch efficacy of white panel traps with panels covered with Sterling's multidimensional color pattern and a blue/black pattern in the field (see photos embedded in Fig. 5 for details). The two color patterns were scanned from the original traps and then printed on an HP photo printer using $28 \times 28 \mathrm{~cm}$ high-quality photo paper (2) and glued onto both sides of the panel trap. Transparent plastic sleeves (10 mil Sur-Flex; $29 \times 29 \mathrm{~cm}$ ) with predrilled $5 \mathrm{~cm}$ holes were coated with diluted Tangle-trap and attached to both sides of the panel traps.

\subsection{Field experiments}

Alsynite and white panel traps (made of polymer mud flaps) were deployed at the University of Nebraska Agricultural Research and Development Center, Ithaca, Nebraska (ARDC), beginning in mid-May. Five pairs of the two types of trap were placed about $3 \mathrm{~m}$ apart and $50 \mathrm{~cm}$ above ground level. The distance between pairs was about $50 \mathrm{~m}$. Traps were monitored daily for three consecutive days, and sticky sleeves were replaced after each check. 


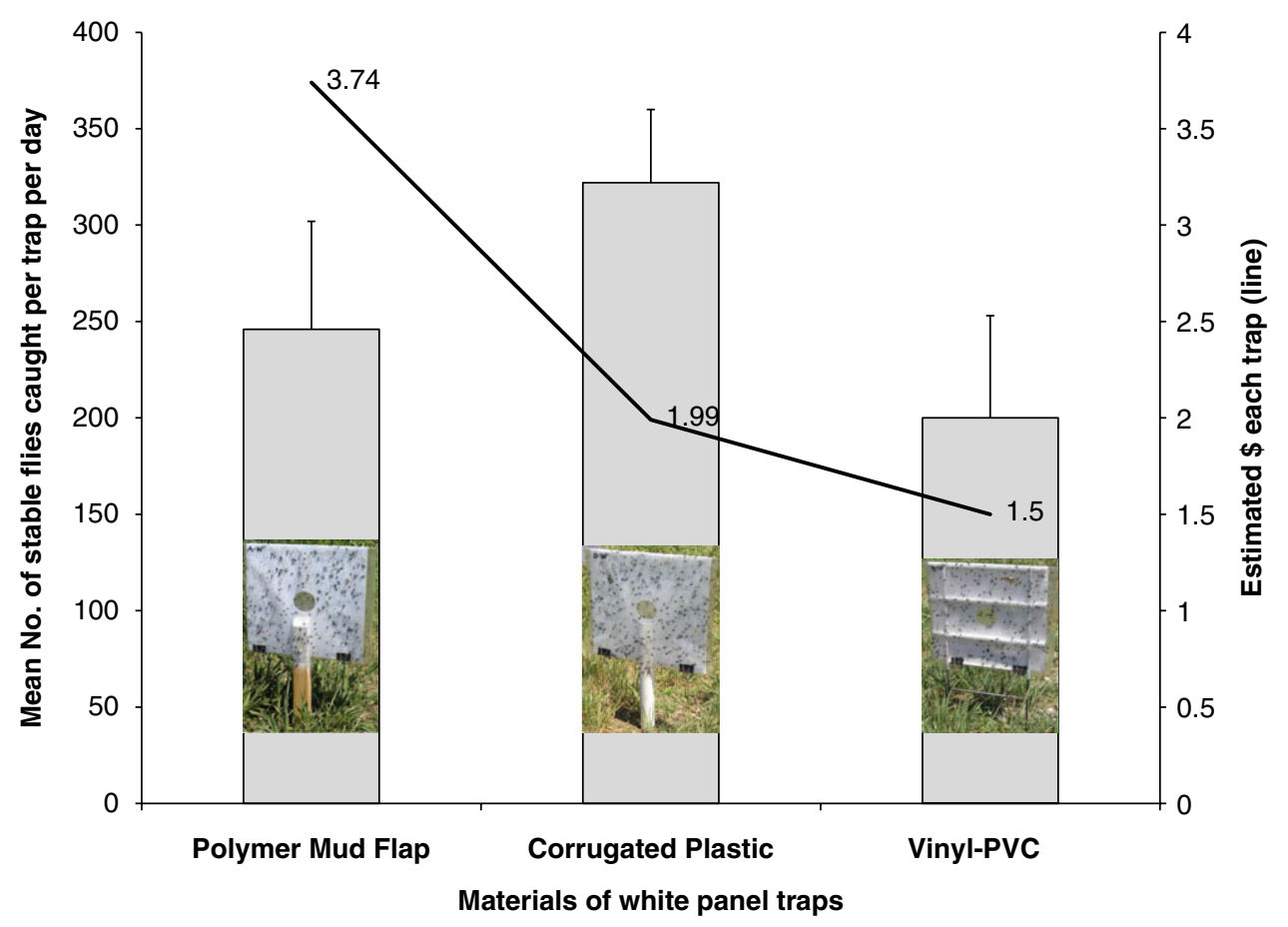

Figure 2. Comparisons of three white panel traps with different materials (columns: stable fly catches) and their estimated costs for prototype trap making (line) at the ARDC.

White panel traps (made of Coroplast corrugated plastic sheets) baited with three odorant lures and with three color patterns were tested in two experiments conducted from May to June in 2012 and 2013. For each experiment, traps were arranged in a randomized completed block, with five replications each. Trap catches were checked daily on weekdays, and plastic sleeves were replaced after each check.

The efficacy of white panel traps baited with $\mathrm{CO}_{2}$ was tested at the ARDC. The test consisted of two pairs of white panel traps, half-equipped with dry ice as a $\mathrm{CO}_{2}$ source and the other half without dry ice, beginning in July 2012. $\mathrm{CO}_{2}$ was delivered by a half-inch hole in an insulated cooler with a $1 \mathrm{~kg}$ block of dry ice placed on top of each trap. Control traps were similarly configured, but lacked dry ice. Pairs of traps were placed about $50 \mathrm{~m}$ apart (the distance between traps within a pair was $3 \mathrm{~m}$ ), trap catches were checked daily for a period of 2 days and sticky sleeves were replaced and trap positions rotated after every check. Stable flies caught on the sticky panels were sexed and examined to determine blood-feeding status in the laboratory.

White panel traps baited with phenol, $m$-cresol or $p$-cresol were tested at the ARDC in 2012 and at a California dairy (Riverside) in 2013. Lures were the same as in the laboratory study and suspended with thin metal wires in the center of the white panel traps. Traps were deployed and checked for 1 week (five replicates) at each site. Total catches of stable flies caught (per trap) were used for data analysis. Trap catches were analyzed with negative binomial ANOVA (Proc Glimmix, SAS 2012).

\section{RESULTS}

\subsection{Comparison between Alsynite and white panel sticky traps}

Stable fly mean captures per day for the two trap types were significantly different during early summer $2012(t=2.78$; $P<0.001)$
(Fig. 1). Mean fly captures in white panel traps were over twice those from Alsynite traps.

\subsection{White panel traps}

Three different materials, polymer mud flaps, Coroplast ${ }^{\circledR}$ and vinyl-PVC, were selected for white panel traps, based on availability and cost. Average per trap costs were \$US 3.74, 1.99 and 1.50 for traps constructed of polymer mud flap, Coroplast ${ }^{\circledR}$ and vinyl-PVC respectively (Fig. 2). No differences in stable fly trap captures among trap materials were observed during the field trials $(F=2.62 ; \mathrm{df}=2,15 ; P=0.239)$ (Fig. 2).

\subsection{Spectral responses of stable flies}

The stable fly ERGs were recorded from 305 to $795 \mathrm{~nm}$ for males and females, including young adults and gravid females. Three major peaks of spectral sensitivity were observed, regardless of sex or age, at $330-360 \mathrm{~nm}, 460-525 \mathrm{~nm}$ and $605-635 \mathrm{~nm}$ (Fig. 3). Differences in ERG responses between the sexes and age groups are listed in Table 1. The strongest ERG responses for all stable flies tested were to ultraviolet light at 330-360 nm ( $F=11.28-18.74$; $\mathrm{df}=3,24 ; P<0.001)$. Significant differences in ERGs were found among male/female and young/old stables flies at longer wavelengths $(t=1.93-2.45 ; P<0.01)$, whereas no differences were found between male and female adult flies at ultraviolet wavelengths $(t=0.47 ; P>0.05)$.

\subsection{Laboratory evaluation of three different colored cylinder traps}

The effectiveness of cylindrical traps (Rescue Trapstick ${ }^{\circledR}$ for biting flies) with or without colors added (yellow and white) was tested under laboratory conditions. The Trapstick and white traps caught similar numbers of flies $(t=1.20 ; \mathrm{df}=125 ; P=0.46)$, whereas the yellow traps caught the fewest $(t=7.57 ; \mathrm{df}=125 ; P<0.01$ and 


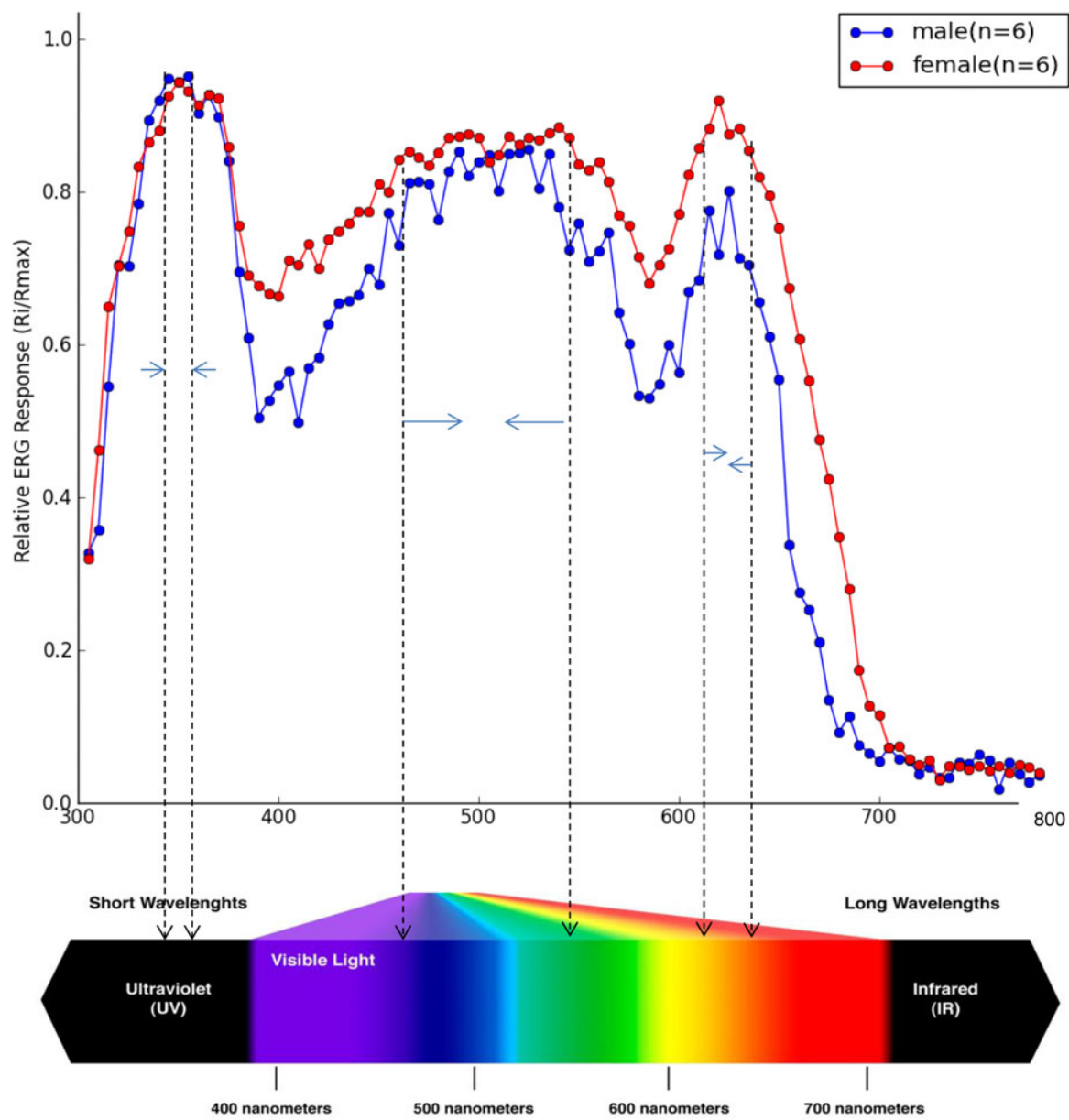

Figure 3. Relative ERG responses from male and female stable flies mirrored with different light wavelengths (modified from the chart http://archive.luxmagazine.co.uk/2012/02/the-doctor-will-see-you-now-2/).

Table 1. Relative spectral sensitivities from ERG recordings among different ages and sexes of stable flies

\begin{tabular}{lllll} 
Colors (wavelengths) & Male adults & Female adults & Young flies & Old flies \\
\hline Ultraviolet $(330-360 \mathrm{~nm})$ & $0.91 \pm 0.02 \mathrm{a}$ & $0.90 \pm 0.02 \mathrm{a}$ & $0.88 \pm 0.02 \mathrm{a}$ & $0.92 \pm 0.02 \mathrm{a}$ \\
Blue $(460-475 \mathrm{~nm})$ & $0.76 \pm 0.02 \mathrm{bc}$ & $0.82 \pm 0.01 \mathrm{~b}$ & $0.80 \pm 0.02 \mathrm{~b}$ & $0.82 \pm 0.01 \mathrm{~b}$ \\
Yellow $(560-600 \mathrm{~nm})$ & $0.62 \pm 0.03 \mathrm{bc}$ & $0.75 \pm 0.02 \mathrm{c}$ & $0.71 \pm 0.03 \mathrm{c}$ & $0.73 \pm 0.02 \mathrm{c}$ \\
Red $(620-650 \mathrm{~nm})$ & $0.67 \pm 0.03 \mathrm{c}$ & $0.85 \pm 0.02 \mathrm{~b}$ & $0.78 \pm 0.02 \mathrm{~b}$ & $0.83 \pm 0.02 \mathrm{~b}$
\end{tabular}

Different letters following means indicate significant differences, ANOVA followed by LSD test, $P<0.05, n=6$.

$t=6.96 ; \mathrm{df}=125 ; P<0.01$ respectively). Old flies ( $9-11$ days old) were caught at nearly double the rate of young flies ( $4-6$ days old) $(t=14.35 ; \mathrm{df}=125 ; P<0.01)$. Because catch counts were cumulative over time, as expected, they varied significantly relative to time $(F=39.90 ; \mathrm{df}=4,125 ; P<0.01)$. Interestingly, the interaction between trap type and fly age was significant $(F=28.85 ; \mathrm{df}=2$, 125; $P<0.01)$. The Rescue Trapstick ${ }^{\circledR}$ was most effective catching older, gravid females, whereas the white traps were more effective catching younger, mixed-sex flies (Fig. 4). None of the interactions with time was significant (trap type*time: $F=0.86$; $\mathrm{df}=8,125 ; P=0.55$; fly age time: $F=0.50 ; \mathrm{df}=4,125 ; P=0.73$; trap type*fly age*time: $F=0.45 ; \mathrm{df}=8,125 ; P=0.89$ ), indicating that the time at which catch counts were made between $30 \mathrm{~min}$ and $24 \mathrm{~h}$ had no effect upon the experimental outcome. The sex ratio of captured flies, although tending towards a female bias, with $55 \%$ females, did not differ significantly from the expected 1:1 $\left(\chi^{2}=19.24 ; \mathrm{df}=11 ; P=0.06\right)$ and did not vary among trap types $(F=0.74 ; \mathrm{df}=2,9 ; P=0.50)$.

\subsection{Field study of stable fly catches from three different colored panel traps}

In the field, more stable flies were caught on the white panel traps than on the Rescue Trapstick ${ }^{\circledR}$ or blue-black traps $(F=25.4 ; \mathrm{df}=2$, 24; $P<0.01$ ) (Fig. 5). Sex ratio did not differ among the three colors of traps $(F=0.73$; $\mathrm{df}=2,24 ; P=0.49)$ but did deviate from the expected 1:1, with $58.7 \%$ males $\left(\chi^{2}=123.9 ; \mathrm{df}=26 ; P<0.01\right)$.

\subsubsection{White panel sticky traps baited with attractant lures}

Overall, white panel sticky traps baited with the synthetic lures caught more stable flies than those without attractants 


\section{Percentage recapture of young stable flies}

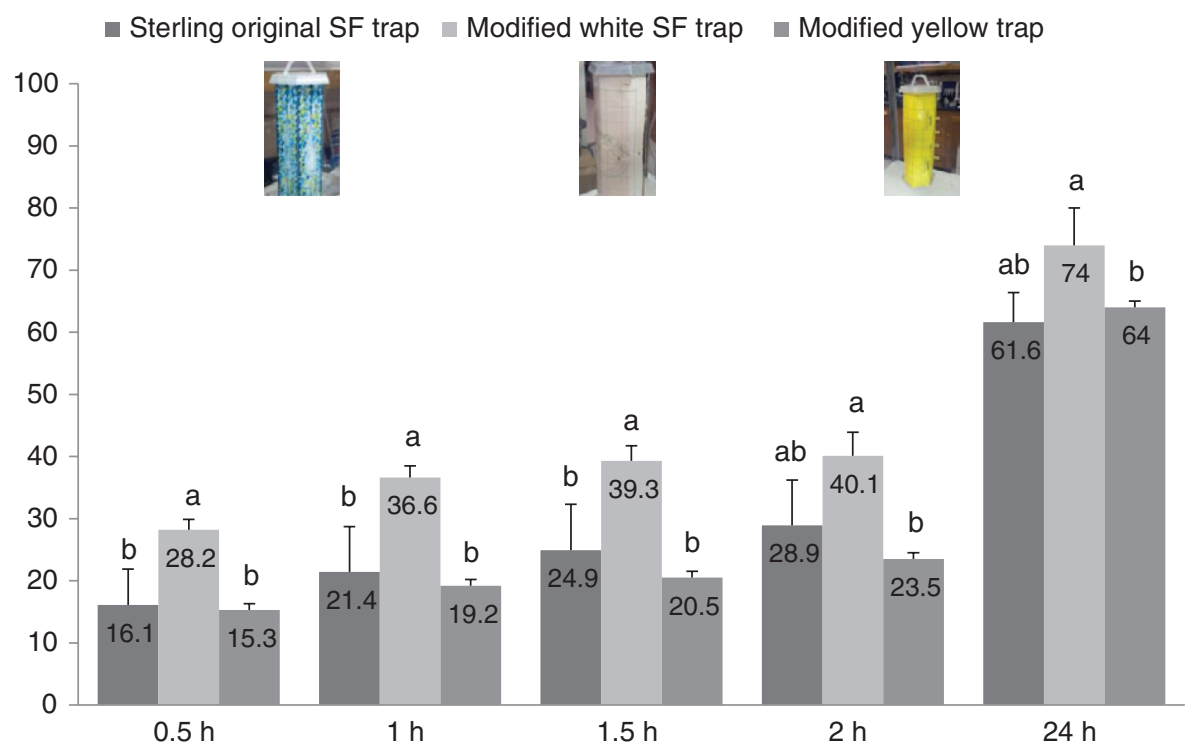

Percentage recapture of gravid stable flies

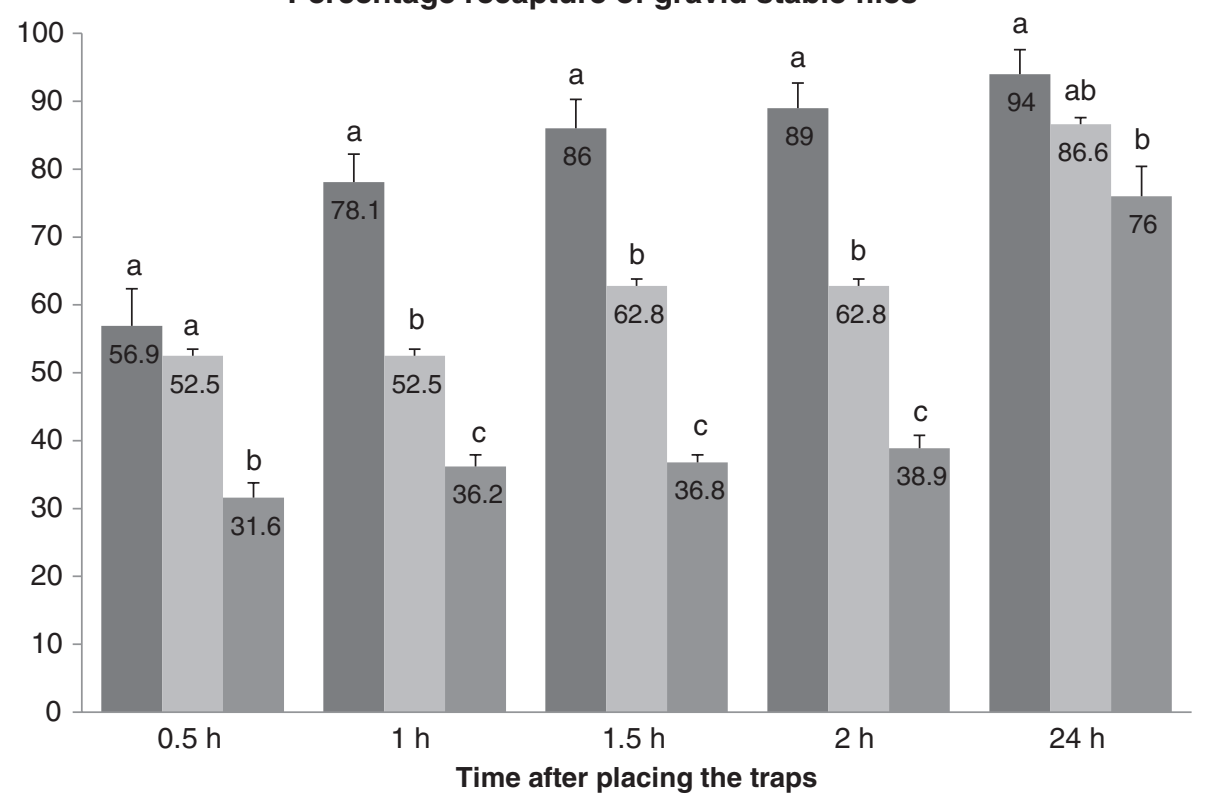

Figure 4. Mean percentiles of recaptured stable flies (young and gravid) observed in the laboratory with different colored Rescue ${ }^{\circledR}$ Trapstik for biting fly traps. Different letters on top of columns indicate significant differences (ANOVA followed by LSD test, $P<0.05$ ).

$(t=3.5-6.6 ; \mathrm{df}=76 ; P<0.01)$ (Table 2). Traps baited with $p$ - and $m$-cresol caught similar numbers of flies $(t=0.45 ; \mathrm{df}=76 ; P=0.97)$, whereas traps baited with phenol caught fewer flies than those baited with cresol $(t=2.7-3.1 ; \mathrm{df}=76 ; P<0.05)$, but more than unbaited traps $(t=3.5 ; \mathrm{df}=76 ; P<0.01)$. Although fewer flies were collected during the California trial $(t=32 ; \mathrm{df}=76 ; P<0.01)$, the interaction term between site and attractant was not significant $(F=1.97 ; \mathrm{df}=3,76 ; P=0.13)$, indicating that the response of the flies to the attractants was similar between the two locations.

Stable fly catches from white panel sticky traps baited with dry ice were $>4$ times higher than those from the unbaited traps $(F=61.1 ; \mathrm{df}=1,12 ; P<0.01)$ (Fig. 6). The number of stable flies captured was higher during the period from 10 a.m. to 4 p.m. than that from 4 p.m. to 10 a.m. $(F=19.3 ; \mathrm{df}=1,12 ; P<0.01)$. No interaction between treatment and time was observed $(F=3.5$; $\mathrm{df}=1,12 ; P=0.09$ ). The percentage of flies that had recently blood fed did not differ between $\mathrm{CO}_{2}$-baited and unbaited traps $(F=0.2$; $\mathrm{df}=1,6 ; P=0.66)$.

\section{DISCUSSION}

The availability of an attractant for a pest species offers great potential for its application in population monitoring and control. Williams ${ }^{10}$ demonstrated the selective attraction of Alsynite plastic to stable flies. Agee and Patterson ${ }^{24}$ considered the attraction of stable flies to Alsynite to be visual and the result of differential UV reflectance in the range $360-429 \mathrm{~nm}$. Our ERG data from both male and female stable flies indicated strong responses to light in 


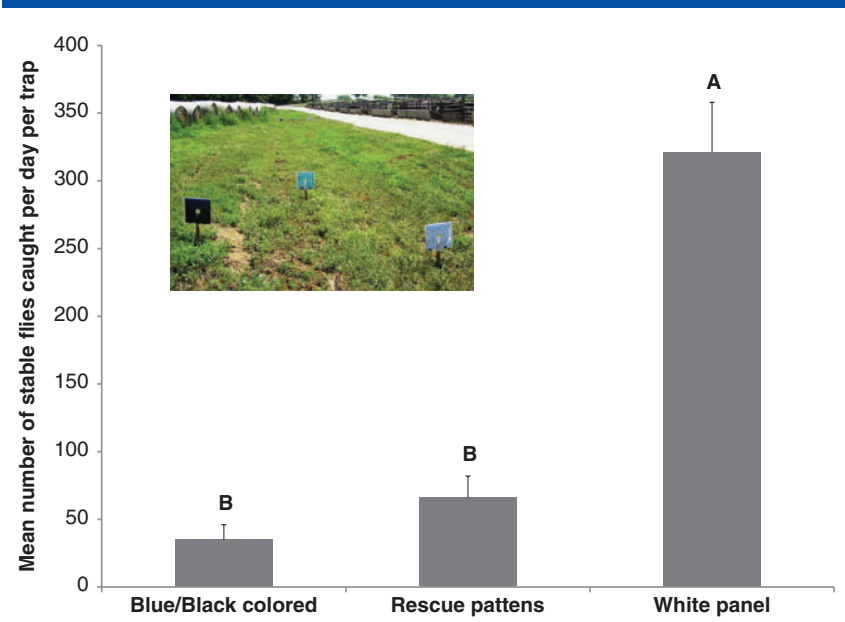

Figure 5. Mean numbers of stable flies captured in panel traps with three different colors and patterns in the field at the ARDC. Different letters on top of columns indicate significant differences (ANOVA followed by LSD test, $P<0.05$ ).

the 330-360 nm UV range (Fig. 4 and Table 1). Similar results were reported by Driggers, ${ }^{25}$ especially when UV light was placed in a dark environment.

Stable flies are diurnal, typically active during late morning and early afternoon. Our field trapping experiment showed significantly more stable flies caught during this time period than during late afternoon and evening. This indicates that visual cues may contribute to their host-seeking behaviors. Pickens and Hayes ${ }^{11}$ found that white pyramid traps were very attractive to stable flies. The spectral reflectance characteristics of white and light pink are quite similar for wavelengths from 330 to $400 \mathrm{~nm}$, to which a strong ERG response peak at $330-360 \mathrm{~nm}$ was observed in the present study (Fig. 4). Our laboratory trapping studies showed that young stable flies are more attracted to modified white Rescue ${ }^{\circledR}$ traps (Fig. 5). However, for gravid females, blue traps are more attractive, with a relative significant ERG response around $480 \mathrm{~nm}$. This is consistent with the results of Jeanbourquin, ${ }^{21}$ who showed that gravid female stable flies fly upwind only while blue-colored objects are present. Taylor and Berkebile ${ }^{12}$ observed that the blue/black Nzi trap collected an older component of the stable fly population relative to that collected by Alsynite and BiteFree ${ }^{\circledR}$ traps. Yellow is the least attractive color, which is similar to results reported by Agee and Patterson ${ }^{24}$ and Taylor and Berkebile. ${ }^{12}$ Our ERG recordings from both sexes of stable flies also display their lower relative responses $(0.62-0.75)$ compared with other sensitive colors, such as UV, red and blue $(0.76-0.91$ for males and $0.82-0.90$ for females). Based on these findings, more laboratory and field tests will be conducted using the panel traps, but with different colors to demonstrate whether colors can also be used to enhance trap efficiency. When we compared the black/blue strip and white panel traps in the field, more stable flies were caught on the white panel traps. White actually is not a color, but a combination of all colors. The relatively strong attraction of stable flies to white traps could be the result of synergistically active wavelengths, including red, green and blue. Foil and Younger ${ }^{16}$ reported that stable flies are highly attracted to half-blue and half-black targets, but the panel traps with these colors caught 6-8 times fewer stable flies than did the white panel traps. This disagreement suggests that other factors may play a role in preference, such as surface texture. It may further be due to the fact that black

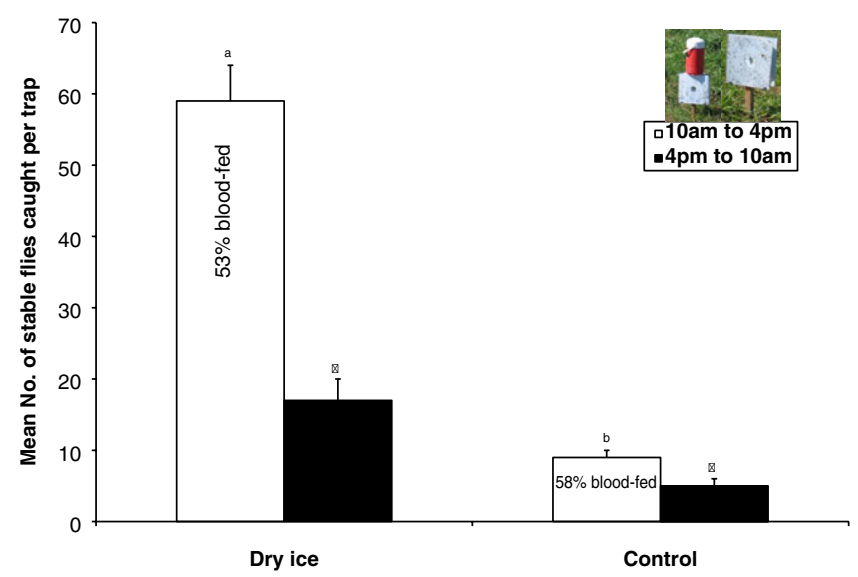

Figure 6. Comparisons of stable fly catches in white panel traps (mean number per trap per day, blood-fed stage and different trapping times) baited with or without dry ice at the ARDC (Student's $t$-test, $P<0.05$ ).

Table 2. Stable fly catches from attractant-baited white panel traps in two US states (means \pm SE)

\begin{tabular}{lrrrr} 
Sites of trapping & Phenol & $p$-Cresol & $m$-Cresol & Control \\
\hline $\begin{array}{c}\text { Ithaca, NE (ARDC, } \\
\text { June 2012) }\end{array}$ & $250 \pm 36$ a & $278 \pm 40$ a & $300 \pm 43$ a & $127 \pm 18 b$ \\
$\begin{array}{c}\text { Riverside, CA } \\
\text { (dairy farm, } \\
\text { June 2013) }\end{array}$ & $5 \pm 1$ bc & $10 \pm 2 a b$ & $11 \pm 2 a$ & $3 \pm 1 \mathrm{c}$ \\
& & & & \\
\end{tabular}

Different letters following the means indicate significant differences, ANOVA followed by LSD test, $P<0.05, n=5$.

absorbs all colors, and thus does not reflect any of the sensitive colors.

Visual attraction (signal) appears to play an important role in flight orientation of stable flies and as a long-distance attractant. However, odor is a critical factor for short-distance orientation and eventual contact and landing. Trap catch can be further enhanced by the combination of olfactory and visual attractants reducing the targeted stable fly population to below the economic threshold more efficiently. ${ }^{26,27}$ With increasing costs for livestock maintenance, any economically sound strategy will benefit the producers tremendously. Several studies have reported that traps equipped with attractant lures can significantly increase trap catches. ${ }^{28-30}$ We have found similarly that white panel traps baited with dry ice can boost trap captures up to sixfold. Among the captured stable flies from white panel traps, about 59\% are blood fed, similar to the ratio reported by Taylor and Berkebile ${ }^{12}$ from Alsynite traps. These results are not surprising because carbon dioxide $\left(\mathrm{CO}_{2}\right)$ is considered to be a powerful attractant for most blood-seeking insects. ${ }^{7,30,31}$ However, $\mathrm{CO}_{2}$ baits are too expensive to be applied in practical control. Lower-cost and longer-lasting attractants need to be further explored.

Vale and Hall ${ }^{32}$ showed that attractant compounds, such as 1-octen-3-ol and a mixture of tsetse fly attractants containing 1-octen-3-ol, 3-n-propylphenol and 4-methyphenol, significantly increased stable fly catches in F3 and Vavoua traps. ${ }^{33,34}$ However, Alzogaray and Carlson ${ }^{35}$ found 1-octen-3-ol not to be attractive to stable flies. Our previous study on stable fly sensory physiology showed that various olfactory sensilla from stable fly antennae respond to odorants associated with cattle and 
their environments. ${ }^{22}$ Recently, we further demonstrated that several compounds from cattle manure slurry elicited behavioral responses from stable flies under field conditions. ${ }^{23}$ The enhanced trap catches with baited stable fly traps in this study support their future application in stable fly population reduction, as the cost of these lures is relatively low and they last over a week.

The Williams trap, consisting of two translucent Alsynite pieces interlocked at right angles to create four wings and placed vertically in slots cut in wooden stakes, is one of the first stable fly traps developed. However, it is cumbersome and costly, with eight coated sleeves. Broce ${ }^{13}$ developed a cylindrical trap (also Alsynite) that showed similar catch efficiency and was less expensive. Our newly designed white panel trap made of white plastic material captured over 2.5 times more stable flies (Fig. 1) than Alsynite traps (with the same surface areas). The average cost for the prototype white panel trap is less than \$US 3.00 per trap. However, significantly greater savings should be possible if this type of trap were to be commercially mass produced. A similar type of trap was tested by Beresford and Suctcliffe ${ }^{36}$ on a New Jersey dairy farm. Their results also showed that Coroplast traps caught significantly more stable flies than did Alsynite cylinder traps.

In conclusion, both visual and olfactory cues can be used to improve monitoring and management of stable flies. The synergism between vision and olfaction found in stable fly trap catches may enhance overall efficacy for stable fly management.

\section{ACKNOWLEDGEMENTS}

We express our gratitude to Dr. Alec Gery (UC-Riverside), Brad Voelker, Dennis Berkebile and Brian Mills for their technical help with this study, and to Dr Jeffery Aldrich for his constructive comments on an earlier version of the manuscript.

\section{REFERENCES}

1 Zumpt F, The Stomoxyine Biting Flies of the World. Gustav Fisher Verlag, Stuttgart, Germany, pp. 1-175 (1973).

2 Taylor DB, Moon RD and Mark DR, Economic impact of stable flies (Diptera: Muscidae) on dairy and beef cattle production. Med Vet Entomol 49:198-209 (2012).

3 Cilek JE and Greene GL, Stable fly (Diptera: Muscidae) insecticide resistance in Kansas cattle feedlots. J Econ Entomol 87:275-279 (1994).

4 Marcon PCRG, Thomas GD, Siegfried BD and Campbell JB, Susceptibility of stable flies (Diptera: Muscidae) from southern Nebraska beef cattle feedlots to selected insecticides and comparison of 3 bioassay techniques. J Econ Entomol 90:293-298 (1997).

5 Somme L, The number of stable flies in Norwegian barns and their resistance to DDT. J Econ Entomol 51:599-601 (1985).

6 Pitzer JB, Kaufman PE and Tenbroeck SH, Assessing permethrin resistance in the stable fly (Diptera: Muscidae) in Florida by using laboratory selections and field evaluations. J Econ Entomol 103:2258-2263 (2010).

7 Gersabeck EF, Merritt RW and Haefner JD, An efficient trap for collecting wild adult stable flies, Stomoxys calcitrans (Diptera: Muscidae), for mark release studies. J Med Entomol 51:541-544 (1982).

8 Hogsette JA, An attractant self-marking device for marking field populations of stable flies with fluorescent dusts. J Econ Entomol 76:510-514 (1983).

9 Meifert DW, Patterson RS, Whitfield T, Labrecque GC and Weidhaas DE, Unique attractant-toxicant system to control stable fly populations. J Econ Entomol 71:290-292 (1978).

10 Williams DF, Sticky traps for sampling populations of Stomoxys calcitrans. J Econ Entomol 66:1279-1280 (1973).

11 Pickens LG and Hayes DK, Evaluation of a new face fly and stable fly (Diptera: Muscidae) trap which segregates the catch of the two species. Environ Entomol 13:1256-1260 (1984).
12 Taylor DB and Berkebile DR, Comparative efficiency of six stable fly (Diptera: Muscidae) traps. J Econ Entomol 99:1415-1419 (2006).

13 Broce AB, An improved alsynite trap for stable flies (Diptera: Muscidae). J Med Entomol 25:406-409 (1988).

14 Rugg D, Effectiveness of Williams traps in reducing the numbers of stable flies (Diptera: Muscidae). J Econ Entomol 75:857-859 (1982).

15 Mihok S, The development of a multipurpose trap (the Nzi) for tsetse and other biting flies. Bull Entomol Res 92:385-403 (2002).

16 Foil LD and Younger CD, Development of treated targets for controlling stable flies (Diptera: Muscidae). Vet Parasitol 137:311 - 315 (2006).

17 Hogsette JA, Nalli A and Foil LD, Evaluation of different insecticides and fabric types for development of treated targets for stable fly (Diptera: Muscidae) control. J Econ Entomol 101:1034-1038 (2008).

18 Kristensen PK and Sommer C, Ammonia and 1-octen-3ol as attractants for Haematopota pluvialis, Hybomitra expollicata (Diptera: Tabanidae) and Morellia spp. (Diptera: Muscidae). J Med Entomol 37:984-985 (2000).

19 Improved attractants for enhancing tsetse fly suppression: final report of a coordinated research project 1996-2002. IAEA-TECDOC-1373 FAO/IAEA, International Atomic Energy Agency, Vienna, Austria (2003).

20 Birkett MA, Agelopoulos N, Jensen KMV, Jespersen JB, Pickett JA, Prijs $\mathrm{HJ}$ et al., The role of volatile semiochemicals in mediating host location and selection by nuisance and disease-transmitting cattle flies. Med Vet Entomol 18:313-322 (2004).

21 Jeanbourquin $\mathrm{P}$, The role of odour perception in the sensory ecology of the stable fly, Stomoxys calcitrans L. PhD dissertation, Université de Neuchâtel, Neuchâtel, Switzerland (2006).

22 Tangtrakulwanich K, Chen H, Baxendale F, Brewer G and Zhu JJ, Characterization of olfactory sensilla of Stomoxys calcitrans and electrophysiological responses to odorant compounds associated with hosts and oviposition media. Med Vet Entomol 25:327-336 (2011).

23 Tangtrakulwanich K, Albuquerque TA, Brewer G, Baxendale F, Zurek L, Miller DN et al., Behavioral responses of stable flies to cattle manure slurry associated odourants. Med Vet Entomol 29:82-87 (2015).

24 Agee HR and Patterson RS, Spectral sensitivity of stable, face and horn flies and behavioral responses of stable flies to visual traps. J Econ Entomol 12:1823-1828 (1983).

25 Driggers DP, Field evaluation of blacklight electrocutor grid traps for the control of flies associated with poultry. MSci thesis, University of Florida, Gainesville, FL, 34 pp. (1971).

26 Campbell JB, Skoda SR, Berkebile DR, Boxler DJ, Thomas GD, Adams DC et al., Effects of stable flies (Diptera: Muscidae) on weight gains of grazing yearling cattle. J Econ Entomol 94:780-783 (2001).

27 Catangui MA, Campbell JB, Thomas GD and Boxler DJ, Calculating economic injury levels for stable flies (Diptera: Muscidae) on feeder heifers. J Econ Entomol 90:6-10 (1997).

28 Nelson RL, Carbon dioxide as an attractant for Culicoides. J Med Entomol 2:56-57 (1965).

29 Wilson $\mathrm{BH}$, Tugwell NP and Burns EC, Attraction of tabanids to traps baited with dry ice under field conditions in Louisiana. JMed Entomol 3:148-149 (1966)

30 Hoy JB, Trapping stable flies by using $\mathrm{CO}_{2}$ or $\mathrm{CO}$ as attractants. J Econ Entomol 63:792-795 (1970).

31 DeFoliart GR and Morris CD, A dry ice-baited trap for the collection and field storage of hematophagous Diptera. J Med Entomol 4:360-362 (1967).

32 Vale GA and Hall DR, The role of 1-octen-3-ol, acetone, and carbon dioxide in the attraction of tsetse flies, Glossina spp. (Diptera: Glossinidae), to ox odor. Bull Entomol Res 75:209-217 (1985).

33 Holloway MTP and Phelps RJ, The responses of Stomoxys spp. (Diptera: Muscidae) to traps and artificial host odours in the field. Bull Entomol Res 8:51-55 (1991).

34 Mihok S, Kangethe EK and Kamau GK, Trials of traps and attractants for Stomoxys spp. (Diptera: Muscidae). J Med Entomol 32:283-289 (1995).

35 Alzogaray RA and Carlson DA, Evaluation of Stomoxys calcitrans (Diptera: Muscidae) behavioral response to human and related odors in a triple cage olfactometer with insect traps. J Med Entomol 37:308-315 (2000).

36 Beresford DV and Sutcliffe JF, Studies on the effectiveness of Coroplast sticky traps for sampling stable flies (Diptera: Muscidae), including a comparison to Alsynite. J Econ Entomol 99:1025-1035 (2006). 